\title{
Priorities and development perspectives of pedagogical specialities and environmental training
}

\author{
Irina Akhmetshina ${ }^{1,{ }^{*}}$, Natalia Filina $^{2}$, Elena Petrova $^{1}$, and Khadriya Yusupova ${ }^{1}$ \\ ${ }^{1}$ State University of Humanities and Technology, 142600 Zelenaya street, 22, Moscow Region, \\ Orekhovo-Zuevo, Russia \\ ${ }^{2}$ Russian State Social University, 129226 Moscow, Wilhelm Pieck street, 4, build., Russia
}

\begin{abstract}
The increasing of the teachers' professionalism is the priority and the necessary condition of the modernization the educational system in the Moscow region. The state educational organizations of secondary vocational and higher education solve this task through the connection with the local authorities of the Moscow Region educational municipalities. Method of theoretical analysis and systematization of scientific ideas; study and analysis of regulatory document were used. The conducted research allowed substantiating the priorities and prospects for the pedagogical specialties development in colleges through the necessity to implement the fundamental goals of continuing pedagogical education. The activity of the Moscow region pedagogical colleges focused on the next key points: the increasing of the raising the profile of the teaching profession; the increasing of the number of students, participating in the professional competitions; the development and integration of the digital tools into the educational process; the increasing of the percentage of graduates ' employment and retention in the profession; motivation to obtain higher education; training of persons with disabilities; introduction of the electronic resources' system in the training process in the context of a pandemic, restrictive measures and the use of distance education opportunities.
\end{abstract}

\section{Introduction}

Moscow region is one of the most dynamically developing regions in The Russian Federation. From January 1, 2021 it is on the second place in terms of population (7 million 691 thousand people) among the regions of the Russian Federation, second only to Moscow. We can see sustainably developing dynamic of increasing population of preschool and primary school age children, during last years.

During his annual appeal, A.U. Vorobev, the governor of the Moscow region, pointed, that they constructed 50 new schools during 2019-2020 years, 33 of them are completed in 2020. However, besides the building of the modern educational centers and the developing of existing schools, the very important question is staffing of the education system in the

\footnotetext{
*Corresponding author: irenaveger@gmail.com
} 
region. There was a shortage of more than 100 of teachers in such specialties as" Primary School Teacher"," Physical Culture», «Music education" on September 1, 2020. The most popular specialty is still «Preschool education». Nowadays, there are near 2 thousand preschool educational organizations, including 502 rural kindergartens and 10 remedial ones. In the Moscow region, the necessity of stuff is checking yearly, it helps to make a quick response to the demands of the regional labor market.

The forecast of the long-term socio-economic development of the Russian Federation for the period up to 2036, developed by the Ministry of Economic Development of the Russian Federation, assumes the necessity of formation of the a flexible and diversified system of vocational education that meets the requirements of the labor market and the needs of the innovative economy, both in terms of educational programs and in terms of conditions and material and technical equipment of the learning process.

The Federal Law «About an education in the Russian Federation» sets the necessity of making the conditions for free functioning and developing of educational system of the Russian Federation as one of the main tasks of regulation in educational sphere. During our study, we have pointed a number of scientific theoretical and methodological works that reveal the phenomenon of continuous professional training of teachers. In particular, the problem of implementation the federal state educational standard has sharply identified the necessity for further development of this research area.

E.F. Zeer, V.S. Tretyakova \& M.V. Zinnatova pointed the essential idea of continuing education, he said, «it accompanies professional development, determines its individual trajectories, determines the formation and development of the main personality neoplasms » $[1]$.

The analysis of the theoretical, methodological and conceptual basis of professional training is in the works of V.I. Blinov, A.I. Satdykov, I.S. Sergeev, N.F. Rodichev [2], V.V. Malenkov [3], T.N. Pankova [4], P. Bishop, A. Hines, T. Collins [5], J. Muller [6], I. Timostsuk, A. Ugaste, L. Kailas [7] etc. The methodology and the theoretical basis of organization and managing of the pedagogical education is covered in the different experimental research and scientific works of A.V. Bychkov [8], O.A. Voskrekasenko, S.N. Igoshin [9], O.V. Kopovaya [10], R.M. Petruneva, V.D. Vasil'eva, U.V. Petruneva [11], D. Beijaard, P.C. Meijer, N. Verloop [12], R.W. Lent, S.D. Brown [13], M.M. Robles [14] etc

The establishment of the facilities, which provide the availability of education, regardless of student's domicile, the training and consolidation of scientific and pedagogical stuff in education and science and increasing the competitiveness of Russian education in the global labor market in general are the main tasks of For high-quality personnel training in the educational cluster of the Moscow region in the context of the rapid development of the modern economy.

\section{Materials and methods}

During our study, we used the method of theoretical analysis and systematization of scientific ideas; study and analysis of regulatory documents. The monitoring methods for studying the need for graduates of the pedagogical profile of colleges in the Moscow region were used. The registration method let us to identify measures to support young professionals, their consolidation in the educational organizations of the Moscow region. The analysis of training programs in pedagogical specialties was carried out in 6 colleges. 


\section{Results}

Modern society has posed a number of serious challenges to the education system of the Moscow Region:

- the growing necessity of teaching staff with higher education;

- the necessity to improve the skills of teachers to meet the requirements of federal state educational standards;

- creating conditions for the involvement of the most prepared and motivated applicants in the pedagogical specialty with their subsequent employment in the received specialty;

- the retention of young teachers in the profession.

There are six secondary vocational education organizations, which provide the training of pedagogical stuff in Moscow region. (GBOU CPO "Moscow Regional College of Arts and Technologies», GOU CPO «Istra Professional College», GBOU SPO "Zaraisk Pedagogical College named after V. V. Vinogradov», GAOU SPO MO «Gubernskiy Professional college», Humanitarian and Pedagogical College of GOU VO MO «State University of Humanity and Technologies», and a further the branch of the Moscow Region State University in Noginsk).

Nowadays, the development of vertically oriented educational complexes of continuous pedagogical education system is finished. They become the important elements of the regional system of professional education. Today, five of six of these pedagogical colleges of Moscow region are in university complexes.

The current system provides a number of significant advantages to colleges: Firstly, the graduates of colleges can continue their education in the universities in the similar specialties. Secondly, the segmentation of professional education and excessive duplication in the training of teaching staff are eliminated, which contributes to improving the quality and efficiency of training qualified specialists. Thirdly, the unification provides the training of new generation specialists, including applied bachelors (near $20 \%$ in 2020), giving them big opportunities to choose the educational trajectories. Finally, the integration gives the big opportunities for providing scientific methodical support for educational organizations, included in the university structure. All these things prove the necessity not only saving the existing professional pedagogical education in Moscow region, but point the perspectives of further development. The areas of such development should include the expansion of the list of educational services provided, as well as building a system of continuing education through the "college - university» model.

\section{Discussion}

Nowadays, there are six secondary vocational education organizations in Moscow region, which provide the pedagogical training programs, with 2,5 thousand students on them. The specialties in which teachers are trained in colleges in the region are:

1. «Preschool education» (Including «Special preschool education»)

2. «Elementary school teacher» (Including «Elementary school teacher with English language ")

3. «Physical training»

4. «Fine Art and drafting»

5. «Musical education»

6. «Further education» (choreography)

The distribution of the training of the future teachers in the Moscow region, according to the programs of secondary vocational education, in the specialties of the pedagogical profile is represented in Table 1. 
There are such recognized educational organizations-leaders as the Istra and Gubernskiy Professional Colleges, which have repeatedly won prestigious awards, among the colleges that train teachers for the Moscow region. Both of them repeatedly became the contest laureate of «100 best SSUZ of Russia». Istra Professional College became the first holder of the Certificate of compliance with the requirements of GOST " Quality Management Systems», and won in the competition of the priority national project "Education". The college is also included in the National Register of "Leading Educational Institutions of Russia".

Table 1. The number of training programs for future teachers in colleges in the specialties of the pedagogical profile.

\begin{tabular}{|c|c|c|c|c|c|c|}
\hline 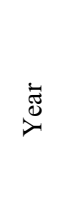 & 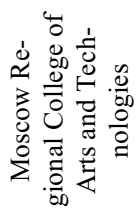 & 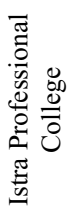 & 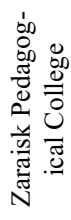 & 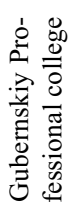 & 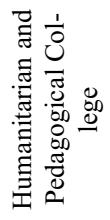 & 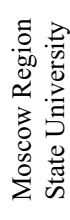 \\
\hline 2016 & 6 & 6 & 3 & 3 & 3 & 6 \\
\hline 2017 & 6 & 6 & 3 & 3 & 4 & 6 \\
\hline 2018 & 4 & 5 & 3 & 4 & 4 & 4 \\
\hline 2019 & 4 & 5 & 3 & 4 & 4 & 4 \\
\hline 2020 & 4 & 5 & 3 & 4 & 4 & 4 \\
\hline
\end{tabular}

The statistical reporting analysis of the necessity for teaching staff, conducted in urban districts and municipal districts of the Moscow region, showed:

The necessity for graduates of educational organizations of secondary vocational education of pedagogical profile in 2018 is 924 people, in 2019 is 720 people, in 2020 is 502 people, in 2021 is 483 people. We can see the tendency of the increasing need in pedagogical stuff; the most demanded profile is «teacher of a preschool educational organization». The least popular specialties are "teacher of an extended day group", "coach of a children's and youth sports school"

Nowadays the number of teaching staff of municipal educational organizations (including additional and preschool education) is 21932 people, of which 9440 people (43\%) are with experience up to 5 years, 5481 people $(25 \%)$ are retirement age. The vacancies for the 20212022 academic year are indicated in the number of 454.5 rates and are announced for teachers in the following subjects:" elementary classes"," mathematics"," Russian language and literature"," physical education", "labor"," technology"; as well as" teacher of a preschool educational organization "and "music director".

The number of young specialists employed in municipal educational organizations in the number of 844 people was $710(84.12 \%)$.

The measures to support young specialists of pedagogical specialties in the Moscow region are carried out mainly at a high and medium level. They include:

- The provision of service housing or dormitories;

- The possibility to participate in the mortgage-lending program;

- The payment of a one-time allowance to college graduates;

- The monthly municipal supplement for the young specialists; 
- Creating the conditions for the industrial and professional adaptation of the young specialists;

- The benefits for enrolling children in kindergartens of the municipal district;

- Compensation for the cost of travel to the place of work and back from one locality to another;

- Compensation for the cost of housing and utilities;

- One-time cash payment for the construction and purchase of housing;

- Spa treatment;

- The recreation in boarding houses and holiday homes.

The information on the number of graduates of municipal educational organizations sent to state educational organizations of higher or secondary vocational education subordinate to the Ministry of Education of the Moscow Region for targeted training in pedagogical specialties in 2020 was received of 293 people. Schools conclude contracts mainly in the following specialties: "primary education", "physical education", "mathematics and computer science", "history and social studies", "Russian language and literature", "biology and chemistry", "psychology".

The mission of the pedagogical colleges consists of not only the training of teaching stuff, but also the dissemination of best practices in the field of teacher education. The colleges intensively connect with educational institutions of preschool and elementary school education, giving their students a methodical support. The teacher develop and realize the refresher programs on topical issues of teacher education.

There are various training and methodological and educational centers, based on the colleges. Istra Professional College successfully operates the Pre-school Education Center "Planeta detstva". Moscow Regional College of Arts and Technology (Yegoryevsk) has an Interscholastic Methodological Center. The Resource Educational Center operates in the Gubernskiy Professional College.

The purposeful work is being carried out in the schools of the Moscow region, on the professional orientation of graduates to study in pedagogical specialties in colleges.

The professional orientation of school graduates is carried out in the following areas:

- The diagnostics of professional interests and aptitudes of students (survey, testing, questionnaire);

- Professional enlightenment (acquaintance of graduates with the social policy carried out in the state and the district aimed at the development of education and support of the teacher corps; thematic class hours; visits to educational institutions to get acquainted with the profession; thematic seminars; design of information stands, booklets; holding exhibitions and forums; acquaintance of graduates with advertising offers of pedagogical colleges of the Moscow region);

- Professional consultation (conversations with graduates and their parents, consultations with an educational psychologist);

-Professional selection (career guidance games, trainings, essay contest "My future profession", preparation of professional charts);

- Professional adaptation (elective courses, teacher classes, practice of work of high school students in the summer health camp at the school);

- Professional education (actions, days of self-government, meetings with veterans of pedagogical work);

- "Professional Trial days", which allow students to learn more about their chosen profession

- Holding mass open Days "Go to the college in a right way»;

- Conducting subject Olympiads and competitions. 
Over the past four years, universities and colleges have been actively implementing the project "Teacher's Class", based on the content of the additional program of the career guidance course «Fundamentals of Professional choice. Pedagogy".

Pedagogical class is a project aimed at pre-professional training of schoolchildren, the formation of knowledge about the teaching profession, aimed at attracting the most motivated and prepared school graduates to enroll in the programs of pedagogical training. The project was made for the students of grades 10-11, who are interested in the teaching profession.

There are 20 pedagogical classes in the Moscow region, in which more than 300 students are trained:

- municipal teacher training classes in the cities of Klin, Elektrogorsk, Pavlovsky Posad, Istra on the basis of methodological centers or departments of education;

- teacher training classes based on schools in the cities of Mozhaisk, Volokolamsk, Shakhovskaya, Dmitrov, Elektrostal.

One of the forms of web connection of educational institutions in Moscow region was «the Pedagogical debut». It is contest of professional skills of pedagogical specialties' students in case of educational organizations of secondary and higher education of the Moscow region. In 2019, more than 80 students from 11 educational organizations took part in the contest. This experience helped the universities and colleges of Moscow region to integrate successfully in the championship of working professions WorldSkills Russia in the fields such as «Preschool education» and «Elementary school education».

With the active participation of teacher training colleges, the Resource Center for Teacher Education of the Moscow Region developed and held a new competence "Teaching in primary classes" in the presentation status at the regional and national stages of WorldSkills Russia-2015.

The college teachers act as experts of the regional stages of the championship. The student of the Humanitarian Pedagogical College of GGTU (Orekhovo-Zuyevo) became the silver medalist of the III National Championship in Professional Skills "WorldSkills Russia2015" in Kazan in the competence "Preschool education" for the first time in 2015.

From the December 2015, the selection stage of the WorldSkills Russia based on GOU VO MO «State University of Humanities and Technology ». Nowadays, more than 90 participants from various regions of the Russian Federation have registered. We invite you to take part in these contests.

We would like to note that the constantly growing demand of the Moscow Region for qualified teaching staff contributes not only to the preservation of the historically established system of teacher education, but also to its active modernization. The pedagogical colleges play an important role in meeting the needs of the region's labor market in this system. At the same time, their integration with universities provides an opportunity for a new qualitative push, both in their development and in the development of the entire Moscow region.

The unification promotes the strengthening of material and technical basis and formation of the common educational and scientific infrastructure within integrated institutions.

The secondary vocational institutions are organically included in the structure of universities, while maintaining their stuff composition, high-quality practical orientation of training, retraining and advanced training of teaching staff.

In such conditions, the universities get the further opportunities for their further development, the expanding the list of specialties in accordance with the demands of the labor market in the region, more effective implementation of reduced training programs, ensuring flexibility and variability of education, continuity and accessibility while maintaining high quality education.

Notably, the graduators of colleges, having the basics of theoretical knowledge and practical skills of the teaching profession, are more successful in mastering higher education 
programs and are more motivated for further employment. More than $80 \%$ of graduators of pedagogical specialties were employed in their specialty in 2020.

The interest of college graduates in continuing their studies is evidenced by the data on the number of applicants who entered the universities of the Moscow region in 2010 based on a diploma of secondary vocational education - more than $35 \%$ of the total admission to the training direction "Teacher Education".

All of the teacher training colleges in the Moscow Region have created favorable conditions for people with disabilities to receive secondary vocational education. The academic buildings have the entrances equipped with ramps, two-level handrails, the staff call buttons, the sound beacons and the light displays. The buildings have running lines above the main entrance, and doors and steps are marked with contrasting stripes and circles, and there are tactile warning tiles. All staircases of the buildings have two-level handrails. The educational buildings have the nformation tactile signs and indicators. The mobile ramps and crawler lifts are available to lift wheelchair users to the floors. The colleges have specialized equipment for people with disabilities: stationary and mobile video magnifiers, stationary induction systems, portable induction systems for individual use, radio classes, information terminals, specialized training places.

\section{Conclusions}

During the last five years, Russia has undergone major changes that have served as the basis for modernizing the system of teacher training in the Moscow Region. The strict regulation of the new requirements for school education results, which are detailed in the Federal State Educational Standards for Preschool and Basic General Education, as well as the approval of the professional standard of the teacher, have become factors of fundamental changes in the organization, content and technologies of teacher training.

In autumn 2020, the ministry of Public Education of Russia presented a Strategy for the development of Secondary Vocational Education until 2030. The documents consists of the five priority directions, which connects with updating the content. They are the formation of a new landscape of the network of secondary vocational education, increasing financial stability and targeted support for colleges, improving the skills of employees and developing a culture of professional competitions.

Therefore, the system of pedagogical education in Moscow region should not stop there; it should constantly maintain its competitiveness in the market of educational services of the Russian Federation.

Its existence is a guarantee for the region in solving complex social problems (for example, at the current stage - training teachers of preschool educational institutions; according to the new professional standard of the teacher, they will all have to have a higher education). Therefore, the mobility, the willingness to innovate and interest in concrete results will guarantee the viability of the teacher education system in the region.

\section{References}

1. E.F. Zeer, V.S. Tretyakova, M.V. Zinnatova, Innovative Model of Socio-Professional Development of a Student's Personality, The Education and science journal 22 (3), 83115 (2020) DOI: https://doi.org/10.17853/1994-5639-2020-3-83-115

2. V.I. Blinov, A.I. Satdykov, I.S. Sergeev, N.F. Rodichev, The methods of scenario designing for the development of regional systems of vocational education and training, The Education and science journal 23 (2), 11-38 (2021) DOI: https://doi.org/10.17853/1994-5639-2021-2-11-38 
3. V.V. Malenkov, Functions of civic education: Teachers' priorities, The Education and science journal 23 (3), 35-57 (2021) DOI: https://doi.org/10.17853/1994-5639-2021-335-57

4. T.N. Pankova, Professional mobility of a modern specialist: additional and continuous professional education, Modern Economics: problems and solutions 1, 68-81 (2016) DOI: https://doi.org/10.17308/meps.2016.1/1373

5. P. Bishop, A. Hines, T. Collins, The current state of scenario development: An overview of techniques, Foresight 9 (1), 5-25 (2007) DOI: https://doi.org/10.1108/14636680710727516

6. J. Muller, The future of knowledge and skills in science and technology higher education, Higher Education 70, 3, 409-416 (2015) DOI: https://doi.org/10.12973/ejmste/80787

7. I. Timostsuk, A. Ugaste, L. Kailas, Factors that Affect Occupational Choice for Future Teachers in Estonia, ICEEPSY 2016: 7th International Conference on Education and Educational Psychology, 2016; 2016 Oct 10-15. Rhodes, Greece, 229-239 (2016) DOI: https://doi.org/10.15405/epsbs.2016.11.24

8. A.V. Bychkov, Standards of Continuity: School-College, Standards and Monitoring in Education 6, 5 (2017) DOI: https://doi.org/10.12737/article_5a1bf5e2eddf30.49459841

9. O.A. Voskrekasenko, S.N. Igoshin, Adaptation of college students as a pedagogical problem, Modern science-intensive technologies 4-2, 272-276 (2020) DOI: https://doi.org/10.17513/snt.38009

10. O.V. Kopovaya, Psychological and Pedagogical Analisis of the Problem of Formation of Teacher's Professional Culture, Penza Psychological Bulletin 2 (2016) DOI: https://doi.org/10.17689/psy-2016.2.8

11. R.M. Petruneva, V.D. Vasileva, U.V. Petruneva, Modern students: digital being, Pedagogy and Psychology of education 2, 150-160 (2020) DOI: https://doi.org/10.31862/2500-297x-2020-2-150-160

12. D. Beijaard, P.C. Meijer, N. Verloop, Reconsidering research on teachers' professional identity, Teaching and teacher education 20, 2, 107-128 (2004) DOI: https://doi.org/10.1016/j.tate.2003.07.001

13. R.W. Lent, S.D. Brown, Social cognitive model of career self-management: Toward a unifying view of adaptive career behavior across the life span, Journal of counseling psychology 60 (4), 557-568 (2013) DOI: http://dx.doi.org/10.1037/a0033446

14. M.M. Robles, Executive Perceptions of the Top 10 soft skills needed in today's workplace, Business Communication Quarterly 75 (4), 453-465 (2012) DOI: https://doi.org/10.1177/1080569912460400 